\title{
Construção da confiança na América Latina: do Grupo de Contadora ao Grupo do Rio (1983-1990)
}

Eliel Waldvogel Cardoso ${ }^{1}$

\section{Resumo}

O artigo demonstra a importância que o Grupo de Contadora, formado pela Colômbia, México, Panamá e Venezuela, em 1983, para ajudar nas negociações de paz na América Central, teve para formar, em torno de si, um mecanismo de consulta política de grande significação para a superação de antigas rivalidades e para a construção de um ambiente de confiança e cooperação na política latino-americana. Dentre as realizações possibilitadas por esse processo, destacamos a introdução do Brasil, que tradicionalmente despertara desconfiança e temores em seus vizinhos, no conjunto das iniciativas multilaterais da América Latina. Nesse movimento, transparece o protagonismo da Venezuela e a importância das relações bilaterais com o Brasil.

Palavras-chave: Cooperação latino-americana, Grupo do Rio, Grupo de Contadora

\begin{abstract}
The article demonstrates the importance of the Group of Contadora, constituted by Colombia, Mexico, Panama and Venezuela in 1983 to help on the peace negotiations in Central America, in forming around it political consult mechanisms of great significance for overcoming old rivalries and for constructing a trust and cooperation environment in Latin American politics. Among the achievements made possible by this process, we highlight the introduction of Brazil, which traditionally raised suspicion and fears in its neighbors, in the cluster of Latin America multilateral initiatives. In this movement, it appears the Venezuela's role and the importance of its bilateral relations with Brazil.
\end{abstract}

Keywords: Latin American cooperation, Rio Group, Contadora Group

Artigo recebido em: 30/06/2013

Artigo aprovado em: 17/10/2013

\footnotetext{
${ }^{1}$ Mestrando em História Social pela Universidade de São Paulo (USP), Brasil, com bolsa CAPES. Pesquisa atual: As Relações Internacionais na América Latina: Brasil e Venezuela entre 1983 e 1998. E-mail: elielwcardoso@gmail.com

Revista Eletrônica da ANPHLAC, ISSN 1679-1061, n.15, p. 282-306, jul./dez. 2013. 
A Guerra Fria, caracterizada pelo confronto entre dois blocos ideológicos liderados pelas superpotências, impactou sobremaneira a política latino-americana, tanto em sua expressão doméstica como internacional. De maneira geral, os países da região foram encarados como aliados naturais dos Estados Unidos, pertencentes ao chamado campo ocidental. À exceção da experiência cubana, tentativas de implantação de regimes socialistas, ou mesmo de posições neutras, foram mal-sucedidas. Nos casos em que a via eleitoral não foi suficiente para afastar o chamado perigo comunista, recorreuse a diversos artifícios de intimidação e repressão. Quando a década de 1970 chegou ao fim, eram poucas as democracias na América Latina. Quase todos os principais países da região eram governados por militares que, após assumirem o poder com o apoio norte-americano, em diversos casos tentaram conciliar a lealdade com o bloco ocidental e projetos nacionalistas de poder geopolítico e desenvolvimento econômico.

Na Argentina, o governo militar de Jorge Rafael Videla (1976-1981) reprimiu movimentos sociais, comunistas ou não, ao mesmo tempo em que se envolveu em graves disputas fronteiriças com o Chile e o Brasil. Também no caso brasileiro, a ditadura militar levantou suspeitas em seus vizinhos. Além do conflito com a Argentina, envolvendo a construção das usinas de Corpus e Itaipu, o Brasil apoiou o golpe de Estado no Chile e levantou suspeita de pretensões hegemônicas em seus vizinhos amazônicos, que não viam com bons olhos os projetos brasileiros de ocupação da Amazônia. A Venezuela, que não viveu a experiência de ditaduras militares na segunda metade do século XX, passou a implementar, a partir do governo de Carlos Andrés Pérez (1974-1979), uma diplomacia atuante na região latino-americana. Isso se manifestou quando a Venezuela se aproximou do regime cubano e fortaleceu os laços com países centro-americanos e caribenhos, através da concessão de apoio econômico, notadamente para a aquisição de petróleo. O México também se associou a esse último projeto, concedendo facilidades econômicas (SERBIN, 1993, p. 11-12).

Quando começou a década de 1980, os maiores países latino-americanos já não estavam dispostos a priorizar as estratégias norte-americanas para a Guerra Fria, preferindo perseguir o que entendiam como seus próprios interesses econômicos e geopolíticos. A Guerra das Malvinas, que a Argentina promoveu contra o Reino Unido, um aliado do bloco ocidental, e a escalada de ameaças que a Venezuela fez contra a Revista Eletrônica da ANPHLAC, ISSN 1679-1061, n.15, p. 282-306, jul./dez. 2013. 
Guiana se inserem nesse contexto. Também o Brasil entrava em atrito com os Estados Unidos em assuntos de promoção tecnológica (energia nuclear e informática) e se recusava a apoiar os projetos intervencionistas daquele país na América Central (LIMA, 2000, p. 79; OLIVEIRA, 2005, p. 199).

Na América Central, a vitória da Revolução Sandinista em 1979 realimentou os temores de infiltração comunista no continente. Também em El Salvador, o governo pró-Estados Unidos debatia-se contra as guerrilhas insurgentes, assim como na Guatemala. No Panamá, o governo do militar Omar Torrijos obteve uma grande vitória com o tratado de 1977, que garantia a devolução do Canal do Panamá à soberania daquele país (AYERBE, 2002, p. 208). Nisso fora apoiado ativamente pelos governos da Venezuela e do México (Jornal de Brasília, 12/03/1977). Apenas em Honduras e na Costa Rica, o apoio fiel aos Estados Unidos não foi posto em questão. Vemos assim que a formação do Grupo de Contadora se insere em um contexto de fatos que, como escreveu Marcelo Santos (2007), "mostram que os governos, setores sociais, movimentos sociais e partidos políticos latino-americanos lutam pelo rompimento total ou pela reformulação das condições de dependência em que eles se encontram diante dos EUA" (p. 44).

O próprio governo norte-americano contribuiu em alguma medida, para que a situação chegasse a esse ponto. Durante a gestão de Jimmy Carter (1977-1981), os Estados Unidos passaram a pressionar as ditaduras latino-americanas, em função dos inúmeros casos de violações dos direitos humanos. Essa atitude, que visava a responder a insatisfações que se manifestavam no interior do sistema político norte-americano, visava a atingir também os países do bloco socialista. Com efeito, os governos militares na região se viram em situação muito desconfortável, e as relações com o seu aliado do norte foram abaladas. Essa emergência do tema dos direitos humanos na pauta de prioridades da diplomacia norte-americana causou divisões mesmo entre os países da América Latina. O presidente venezuelano Carlos Andrés Pérez, em discurso proferido durante visita aos Estados Unidos, endossou a diplomacia do governo Carter, destacando que ela tinha o potencial para "abalar as raízes corroídas do autoritarismo latino-americano" (Jornal do Brasil, 30/06/1977). Ainda durante o governo de Jimmy Carter, os Estados Unidos hostilizaram o governo da Revolução Sandinista na Revista Eletrônica da ANPHLAC, ISSN 1679-1061, n.15, p. 282-306, jul./dez. 2013. 
Nicarágua, apoiando materialmente os remanescentes da ditadura de Anastasio Somoza. E, nesse esforço, contaram com a ajuda do governo militar da Argentina (BANDEIRA, 2005, p. 448). Em 1980, aviões hondurenhos e outros não identificados invadiam o espaço aéreo da Nicarágua, com apoio dos Estados Unidos (VIAÑA, 1986, p. 146).

Naquele ano de 1980, em que aconteceram as eleições que levaram ao poder Ronald Reagan, membros do Partido Republicano dos Estados Unidos elaboraram o chamado Documento de Santa Fé, em que delineavam uma nova estratégia para atuar na América Latina. Os partidários de Reagan entendiam que a ênfase nos direitos humanos fora um equívoco que afastara aliados dos Estados Unidos, enfraquecendo os esforços desse país naquilo que realmente importava: vencer a Guerra Fria contra o comunismo. O documento preconizava a revitalização do Tratado Interamericano de Assistência Recíproca, que estabeleceu, em 1948, que um ataque realizado por país externo a qualquer país americano seria entendido como um ataque a todos os demais.

A compreensão de que o problema das guerrilhas na América Central, na Colômbia e na Venezuela era atribuível à agressão comunista internacional e deveria ser respondido militarmente se cristalizou no governo de Reagan, desde que ele assumiu o poder, em janeiro de 1981. Naquele ano, os Estados Unidos concederam acesso facilitado ao seu mercado para produtos oriundos da América Central, em parte através de concessões fiscais para empresas que decidissem se instalar na região. Paralelamente, estabeleceram Honduras como a base para suas operações de combate ao comunismo, concedendo, entre 1981 e 1983, US\$300 milhões para compra de armas e treinamento de soldados. O governo de El Salvador, que combatia guerrilhas de orientação esquerdista, recebeu no mesmo período US\$700 milhões para iguais finalidades. Também os contras, remanescentes das forças de Somoza que combatiam o governo revolucionário nicaraguense, receberam auxílios militar e financeiro e atuavam em solo hondurenho, de onde atacavam a Nicarágua pela fronteira norte (AYERBE, 2002, p. 205).

O governo dos Estados Unidos tinha a preocupação de apagar a experiência negativa que foi a derrota no Vietnã e, para isso, lançou mão de uma nova estratégia, denominada low-intensity conflict ou, conflito de baixa intensidade. Essa estratégia era aplicada desde Honduras, contra o governo da Nicarágua e a insurreição salvadorenha, e

Revista Eletrônica da ANPHLAC, ISSN 1679-1061, n.15, p. 282-306, jul./dez. 2013. 
consistia no fornecimento de dinheiro, armas, assessoria e treinamento para os seus aliados, que deveriam fornecer os soldados. Dessa maneira, os norte-americanos buscavam a vitória, sem ter que envolver o uso aberto de seu próprio exército em terras estrangeiras (BANDEIRA, 2005, p. 448; SANTOS, 2007, p. 42).

A valorização da solidariedade pan-americana, prevista no Documento de Santa Fé, sofreu um revés inesperado, quando a Argentina decidiu invadir as ilhas Malvinas para restabelecer sua soberania sobre elas. Contrariamente ao que esperava o governo argentino, os britânicos enviaram considerável força militar para reaver as ilhas, dando início a um confronto entre dois aliados do bloco ocidental, que terminou em uma rápida e inapelável vitória do Reino Unido. A guerra aconteceu entre abril e junho de 1982, e a atitude dos Estados Unidos frente ao conflito, de aberto apoio aos britânicos, surpreendeu os argentinos e muitos latino-americanos. A indisposição que essa atitude gerou na região contra os Estados Unidos pareceu confirmar a previsão da embaixadora norte-americana junto às Nações Unidas, Jeanne Kirkpatrick, que se opusera ao apoio ao Reino Unido, dizendo que tal apoio custaria ao seu país "cem anos de animosidade na América Latina”. A partir do ano seguinte, a Argentina já não cooperou mais com as ações dos Estados Unidos na América Central (BANDEIRA, 2005, p. 448-451).

Em visita ao Brasil, em dezembro de 1982, Reagan procurou apoio brasileiro para o combate ao que via como ameaça comunista na Nicarágua e em El Salvador. Essa visita fazia parte de um giro pela América Latina, que incluía o México e a Venezuela. O presidente norte-americano comparou a ameaça das armas nucleares e dos exércitos convencionais com o perigo representado por "pretensos revolucionários", "armados, a um custo muito elevado pelo preposto de uma potência longínqua, uma potência que esposa uma filosofia alheia às Américas, cujo objetivo é a desestabilização dos nossos governos e das nossas economias" (ALEIXO, 1983, p. 31). À interpretação de Reagan, o presidente brasileiro João Baptista Figueiredo contrapôs a ideia de que "não podem as soluções pluralistas e democráticas prosperar num quadro de pobreza e instabilidade social". Com essa argumentação, não apenas Figueiredo, mas também a maior parte dos líderes latino-americanos, buscou excluir a crise centro-americana do contexto da disputa entre os Estados Unidos e a União Soviética. O presidente do Brasil

Revista Eletrônica da ANPHLAC, ISSN 1679-1061, n.15, p. 282-306, jul./dez. 2013. 
enfatizou a sua confiança de que os países latino-americanos podiam resolver a crise por seus próprios esforços e em seus próprios termos:

\begin{abstract}
Cremos, firmemente, que naquela região (América Central), como nas demais, o direito dos povos e a soberania dos governos devem ser respeitados sem ingerências ou pressões externas. Vemos com grande esperança a contribuição que podem dar à pacificação dos espíritos e à pesquisa de soluções democráticas e livres os países latino-americanos que, como o México, a Venezuela e a Colômbia, aliam uma inestimável experiência política a uma tradicional presença naquela região. (ALEIXO, 1983, p. 31)
\end{abstract}

Mesmo sem o apoio dos grandes países latino-americanos, os Estados Unidos continuaram perseguindo as suas finalidades na América Central, de derrubar o governo da Nicarágua e aniquilar a guerrilha salvadorenha. Para realizar tais objetivos, a via militar foi privilegiada, levando Francisco Rojas Aravena e Luis Guillermo Solís Rivera (1996, p. 113-115) a considerar o período que se estende de 1979 e 1985, como sendo um período de "instabilidade generalizada", marcada pela ofensiva norte-americana. De fato, aproximadamente 10 mil guardas das forças de Somoza se haviam refugiado em Honduras após o triunfo da Revolução Sandinista, e muitos deles ajudaram a compor a guerrilha contrarrevolucionária dos contra (VIAÑA, 1986, p. 146). Ainda que, em um primeiro momento, os Estados Unidos tivessem chegado a destinar apoio humanitário ao governo revolucionário da Nicarágua, esse apoio foi logo retirado como punição pelo apoio dos nicaraguenses à guerrilha da Frente Farabundo Martí de Libertação Nacional (FMLN) (BANDEIRA, 2005, p. 448).

Tal cenário era motivo de crescente inquietação entre os países latinoamericanos. Temia-se tanto o transbordamento dos conflitos, caso as forças em disputa estabelecessem bases de operações em terceiros países, quanto a ingerência norteamericana, que, naqueles dias, podia implicar até mesmo na ocupação militar direta. $\mathrm{O}$ México, a Venezuela e a Colômbia, por sua proximidade geográfica com a região, assim como pelos seus antecedentes de cooperação política, eram os países mais capacitados a fornecer alternativas para a escalada dos confrontos. Esses três países haviam apoiado as negociações do Panamá com os Estados Unidos para a transferência de soberania sobre o Canal, que resultaram no acordo de 1977. A Venezuela e o México haviam assinado, em 1980, os Acordos de San José, pelos quais conferiam auxílio econômico

Revista Eletrônica da ANPHLAC, ISSN 1679-1061, n.15, p. 282-306, jul./dez. 2013. 
aos países centro-americanos e caribenhos, e também assinaram uma declaração conjunta sobre os conflitos entre Nicarágua e Hondura, em setembro de 1982 (GONZALO, 1986, p. 18). Essa declaração conjunta foi precedida pela troca de correspondências a respeito do assunto, em um primeiro momento entre os presidentes da Venezuela, Luis Herrera Campíns, e do México, José López Portillo.

Em outubro de 1982, os dois presidentes propuseram um encontro entre o presidente de Honduras, Roberto Suazo Córdova, e o Coordenador da Junta de Governo de Reconstrução Nacional da Nicarágua, Daniel Ortega. O encontro não se realizou, apesar da aceitação de Ortega, em razão da negativa de Suazo Córdova, que alegou compromissos em seu país. Naquele mesmo mês, o Panamá manifestou interesse em participar da mediação. A esse país não convinha o recrudescimento dos conflitos, porque sediava o Comando Sul do Exército dos Estados Unidos e seria afetado pelas operações militares (VIAÑA, 1986, p. 149). Ademais, as desconfianças panamenhas em relação aos Estados Unidos eram altas naquele momento. Suspeitava-se do envolvimento da CIA no acidente aéreo em que morreu o líder nacionalista do país, Omar Torrijos.

Convém destacar outros antecedentes da diplomacia latino-americana que levaram à formação do Grupo de Contadora. Em uma tentativa de cooperação com a França, em agosto de 1981, o México assinou uma proposta de intermediação dos conflitos, mas a recusa dos Estados Unidos em ceder o protagonismo levou ao fracasso desse projeto. Em janeiro de 1982, a Costa Rica propôs a formação de uma Comunidade Democrática Centro-Americana, que excluísse a Nicarágua e integrasse El Salvador, Costa Rica e Honduras. Quando foi sugerida a aceitação do Panamá, o presidente daquele país recusou dizendo: “A Comunidade Democrática é um dardo dirigido ao coração da Nicarágua". Em fevereiro, a Nicarágua apresentou um plano de paz, em que mantinha a política de não alinhamento, programava eleições para 1985 e se dispunha a assinar pactos de não agressão com Honduras e Costa Rica, mas o plano também não prosperou. Em outubro daquele ano, os Estados Unidos voltariam a propor a formação de uma entidade democrática na região. Em dezembro, o presidente mexicano López Portillo passou a faixa presidencial a seu sucessor, Miguel de La Madrid, que se

Revista Eletrônica da ANPHLAC, ISSN 1679-1061, n.15, p. 282-306, jul./dez. 2013. 
comprometeu a continuar o engajamento de seu país no processo de paz da América Central, em cooperação com a Venezuela (VIAÑA, p. 146-148).

Esse último país tinha seu próprio histórico de envolvimento nos assuntos de seus vizinhos centro-americanos. No primeiro semestre de 1980, a imprensa venezuelana noticiou uma troca de acusações, em que o ex-chanceler Simon Alberto Consalvi acusava o governo de seu país de fornecer armas ao governo salvadorenho, para auxiliar na repressão à "insurgência revolucionária" (Folha de S. Paulo, 02/04/1980). Em maio de 1981, a Venezuela propôs ao Brasil a formação de um mecanismo de consulta política preferencial entre Brasília, Caracas, Cidade do México e Buenos Aires, em moldes muito parecidos com o que viriam a ser os Grupos de Contadora e de Apoio. Mas, naquele momento, a proposta venezuelana foi rechaçada pelo governo brasileiro, que considerou a proposta "elitista" e preferiu apostar em uma “democracia de países” (Folha de S. Paulo, 03/05/1981).

Em novembro daquele mesmo ano, a Venezuela apoiou a contenção da influência do regime cubano na região, ainda que tenha esclarecido que não convinha fazê-lo por meios militares. O governo venezuelano também se opôs à possibilidade de um ataque à Nicarágua e ajudava economicamente o governo daquele país. Enquanto Reagan dava declarações em que alertava para o papel que "forças externas" desempenhavam naquela região, o presidente venezuelano Herrera Campíns preferia enfatizar os "desajustes sociais" que alimentavam o sentimento revolucionário. Mesmo com essas discordâncias, os Estados Unidos venderam à Venezuela 20 aviões de caça, modelo F-16, para ajudar na contenção da ameaça soviética (O Estado de S. Paulo, 18/11/1981). Essa proximidade com os Estados Unidos começaria a diminuir após a Guerra das Malvinas, e, já em 1982 o presidente venezuelano visitou a Nicarágua por ocasião do terceiro aniversário da Revolução. Antes, em maio de 1981, os embaixadores da Venezuela na América Central se reuniram em Manágua para analisar o cenário político regional. Outra reunião entre eles aconteceu em abril de 1982, em Caracas, e ratificou o interesse que a Venezuela devotava ao tema (VIAÑA, 1986, p. 148-149).

Por todos esses antecedentes, é que consideramos ser necessário complementar o que escreveu Alberto van Klaveren (1996, p. 43), segundo quem, a participação no Grupo de Contadora contribuiu para a aproximação entre o México e a Venezuela. Revista Eletrônica da ANPHLAC, ISSN 1679-1061, n.15, p. 282-306, jul./dez. 2013. 
Como vimos, os dois países tinham um histórico de interesse sobre a América Central e mesmo de ações conjuntas nesse âmbito. O mais exato seria considerar a participação em Contadora como um capítulo da cooperação mexicano-venezuelana, que começou antes de janeiro de 1983 (data de formação do Grupo de Contadora) e continuou até, pelo menos, a entrada do México no Tratado de Livre Comércio da América do Norte (NAFTA), em 1994.

Após um período de consultas presidenciais, cujos principais momentos registramos acima, foi decidido estabelecer um grupo de articulação política, em moldes similares ao da proposta venezuelana de 1981. Os chanceleres do México, Bernardo Sepúlveda Amor; da Colômbia, Rodrigo Lloredo Caicedo; da Venezuela, José Alberto Zambrano Velasco; e do Panamá, Juan José Amado se reuniram na ilha de Contadora, Panamá, no dia 8 de janeiro de 1983, dando origem ao que ficou conhecido como Grupo de Contadora.

Antes de nos aprofundarmos sobre as primeiras atuações do Grupo, convém nos referirmos ao outro elemento central da conjuntura da época: a crise da dívida externa. A elevação das taxas de juros praticadas no mercado financeiro internacional atingiu as economias latino-americanas, que haviam tomado emprestadas grandes somas durante a década de 1970. Aqueles empréstimos foram concedidos a taxas de juros variáveis, condicionadas à variação das taxas dos governos dos Estados Unidos e do Reino Unido. A elevação dos juros, nesses países, levou ao aumento abrupto dos serviços da dívida latino-americana, em um momento em que os preços das matérias-primas e outros produtos tradicionais de exportação entravam em um ciclo de baixa no mercado internacional. Em poucos meses, os países latino-americanos viram aumentar os seus encargos financeiros, ao mesmo tempo em que diminuíam suas receitas de exportação. Esse foi o mecanismo que enfraqueceu sobremaneira a capacidade de atuação internacional dos países da região.

No mesmo momento em que esses países se encontravam em uma situação de ofensiva, no que diz respeito à política internacional, articulando um esforço até então inédito de cooperação para afastamento da ingerência norte-americana na América Latina, suas economias se encontravam em posição calamitosa, na qual atravessariam toda a década de 1980 (VIZENTINI, 2004, p. 97-98). O ano de 1982, que precedeu Revista Eletrônica da ANPHLAC, ISSN 1679-1061, n.15, p. 282-306, jul./dez. 2013. 
imediatamente a formação do Grupo de Contadora, foi emblemático para essa situação. Foi esse o ano em que o México declarou sua moratória, por falta de meios de pagamentos. Esse evento passou a ser considerado pela historiografia como sendo o marco inicial do período de crise da dívida. A moratória mexicana logo foi seguida por complicações nos pagamentos do Brasil, Argentina, Peru e Venezuela, dando contornos continentais ao problema (Jornal de Brasília, 28/12/1982).

Não tardou para que a articulação de Contadora fosse adotada como modelo para uma possível união dos devedores, que fosse capaz de fortalecer a posição negociadora dos países latino-americanos frente aos maiores bancos privados internacionais, seus maiores credores. De fato, o próprio Grupo de Contadora, após uma curta fase em que se dedicou exclusivamente ao tema da paz na América Central, evoluiu para uma organização internacional amplificada, em número de membros e de temas que compuseram sua pauta.

\section{Primeiras atuações do Grupo de Contadora}

Após a constituição do Grupo, os EUA enviaram a embaixadora na ONU, Jeanne Kirkpatrick, e Roger Fontaine, assessor presidencial, para visitas ao Panamá, Venezuela, Costa Rica, El Salvador e Honduras. Durante as visitas, os EUA coordenaram manobras militares na fronteira entre a Nicarágua e Honduras, com quatro mil soldados hondurenhos e mil e quinhentos norte-americanos. No âmbito de atuação do Grupo de Contadora, foi constituído um Grupo Técnico, com representantes de todos os países envolvidos nas negociações. Em 1983, foram realizadas cinco reuniões entre os chanceleres do Grupo e os chanceleres dos países centro-americanos. Aconteceram outras cinco reuniões, que contaram apenas com a presença dos chanceleres do Grupo de Contadora (VIAÑA, 1986, p. 152).

Até setembro de 1983, as reuniões versaram, principalmente, sobre os princípios em que estariam assentados os termos de um tratado de paz e sobre a construção da confiança entre as partes envolvidas. Naquele mês de setembro, porém, durante a quarta reunião comum, foi produzido um Documento de Objetivos, composto de 21 pontos, nos quais se retomavam aspectos do direito internacional, estabelecendo mecanismos e coordenando sistemas de comunicação direta, para que se prevenissem e Revista Eletrônica da ANPHLAC, ISSN 1679-1061, n.15, p. 282-306, jul./dez. 2013. 
regulamentassem potenciais conflitos entre os Estados-parte. Desde o começo, o governo dos Estados Unidos se opôs à iniciativa de Contadora. Em resposta à má acolhida que tiveram seus enviados à região, foi constituída a Comissão Kissinger, de caráter bipartidário. Essa Comissão produziu um relatório, no qual admitia a influência do mal-estar social para fomentar a situação revolucionária, mas insistia em enfatizar a instrumentalização do descontentamento por parte de forças estrangeiras: Cuba e União Soviética (VIAÑA, 1986, p. 151). No relatório Kissinger, constava a seguinte afirmação: "Os Estados Unidos não podem usar o processo de Contadora como substituto para sua própria política". O próprio presidente Reagan afirmou ser um contra e recusou-se a receber os chanceleres dos países membros de Contadora (ARAVENA; RIVERA, 1996, p. 117). Essa política consistia em derrubar, através da ação militar, o governo da Nicarágua, suprimindo também os focos revolucionários em outros países.

Houve no Brasil calorosa acolhida para a iniciativa de Contadora. Em dezembro de 1983, 214 parlamentares brasileiros, entre deputados e senadores, enviaram uma carta ao presidente venezuelano, expressando seu apoio às negociações pela paz na América Central conduzidas pelo Grupo de Contadora. Na carta, os parlamentares explicitaram sua preocupação com o crescente envolvimento militar dos EUA na região (Jornal de Brasília, 03/12/1983). Na edição daquele ano da Revista Brasileira de Política Internacional, o presidente de honra do Instituto Brasileiro de Relações Internacionais, ${ }^{2}$ José Carlos Brandi Aleixo, publicou um artigo (1983, p. 21-58), em que ressaltou o apoio que as autoridades brasileiras ofereciam ao Grupo de Contadora. Esse apoio baseava-se em uma percepção comum de que o problema da América Central tinha um caráter estrutural, que se devia mais à situação de desarranjo social do que à intervenção da União Soviética, e que esses problemas deveriam ser resolvidos pelos próprios centro-americanos, em um quadro de respeito aos princípios democráticos e pacifistas da Carta da Organização dos Estados Americanos (OEA), da qual os Estados Unidos faziam parte.

Na Venezuela, o mês de dezembro de 1983 foi marcado pela eleição de Jaime Lusinchi para ocupar a presidência do país, no período entre fevereiro de 1984 e

\footnotetext{
${ }^{2}$ Organização que editava a Revista.

Revista Eletrônica da ANPHLAC, ISSN 1679-1061, n.15, p. 282-306, jul./dez. 2013. 
fevereiro de 1989. Uma vez reconhecida sua vitória nas eleições, Lusinchi reafirmou seu compromisso com os esforços desenvolvidos no âmbito do Grupo de Contadora ( $O$ Estado de S. Paulo, 06/12/1983). Mas as negociações promovidas pelo Grupo estavam em um impasse. A incompatibilidade entre as ideias do Grupo e aquelas expressas pelo relatório Kissinger ganhavam materialidade em janeiro de 1984, enquanto a CIA minava os portos da Nicarágua (VIAÑA, 1986, p. 153). Naquele país, as tensões aumentavam, e um desembarque de tropas norte-americanas era esperado para qualquer momento. Mário Jakobskind, repórter brasileiro, estava na Nicarágua naqueles dias, e apurou informações de que Reagan desistira da invasão, somente após cálculos do Pentágono indicarem a probabilidade de os confrontos resultarem em 10 mil mortos do lado norte-americano, cifra inaceitável para a opinião pública e para o governo, que deveria enfrentar eleições no ano seguinte. Tomás Borge, ministro do Interior da Nicarágua e veterano da Revolução, declarou em entrevista à Agência Cono Sur Press, que apoiava os esforços de Contadora, mas que elas não eram suficientes para afastar a possibilidade de um ataque dos Estados Unidos (JAKOBSKIND, 1985, p. 98-109).

Entre abril e agosto de 1984, a proposta para a paz e o desarmamento apresentada pelo Grupo Contadora sofreu seguidas objeções das partes envolvidas, e não houve avanços. Tais impasses não levaram ao enfraquecimento da determinação dos líderes políticos envolvidos com as negociações. Em visita à Colômbia, nos primeiros meses de $1984^{3}$, o presidente mexicano, Miguel de La Madrid, declarou:

\footnotetext{
Colombia y México, al lado de Panamá y Venezuela hemos manifestado repetidamente que la crisis centroamericana tiene su origen en las injusticias, la explotación, el ejercicio arbitrario del poder y la carencia de instituciones que, desde hace décadas, vive esa castigada región. (...) En América Central se propician afanes intervencionistas pero los enfrentamientos en el área, en sus orígenes y en sus efectos a largo plazo, no obedecen al conflicto EsteOeste. Exigimos que no se mistifique la realidad (apud VIAÑA, 1986, p. 149-150).
}

Também o ex-chanceler da Colômbia, Rodrigo Lloreda Caicedo, que estava no cargo quando foi criado o Grupo, pronunciou-se enfaticamente na Comissão Econômica para a América Latina e Caribe (CEPAL), em fevereiro de 1984:

\footnotetext{
${ }^{3} \mathrm{O}$ autor citado não especificou a data.

Revista Eletrônica da ANPHLAC, ISSN 1679-1061, n.15, p. 282-306, jul./dez. 2013. 
Si fracasamos en Centroamérica perderemos capacidad para enfrentar problemas similares en otras partes. Centroamérica representa un gran desafío. Lo que suceda en esta región influirá en el porvenir de toda América... Contadora pretende ser una política de gran alcance para América Latina. Es muy importante saber si estamos en capacidad de buscar soluciones propias para nuestros problemas, o, por el contrario, estamos condenados a esquemas de dependencia económica y política, impotentes para superar el desarrollo o para eludir la polarización Este-Oeste (apud VIAÑA, 1986, p. 154).

Naquele mês de fevereiro, o líder nicaraguense Daniel Ortega compareceu à cerimônia de posse do presidente venezuelano Jaime Lusinchi, enquanto prosseguiam os bombardeios da Nicarágua por aviões provenientes de Honduras. Ortega foi ovacionado por uma multidão em Caracas, que deu mostras da popularidade das políticas promovidas pelo Grupo de Contadora (JAKOBSKIND, 1985, p. 97). Também estiveram presentes na cerimônia de posse o presidente argentino Raúl Alfonsín, o secretário de Estado norte-americano George Schultz, representantes do Brasil, de Cuba e da União Soviética. De fato, o ecumenismo dessa cerimônia refletia a elevação de Caracas à condição de centro estratégico da política latino-americana. O Brasil enviou seu ministro da Justiça, Ibrahim Abi-Ackel (Correio Braziliense, 03/02/1984; Folha de S. Paulo, 03/02/1984; Jornal de Brasília, 03/02/1984).

No dia sete de setembro de 1984, o Grupo de Contadora apresentou uma nova proposta para a paz às autoridades centro-americanas da Costa Rica, El Salvador, Guatemala, Honduras e Nicarágua. Os Estados Unidos e mais quatro daqueles países inicialmente aprovaram a proposta, mas voltaram atrás depois que a Nicarágua também aprovou. A estratégia dos Estados Unidos e de seus aliados era a de apenas ganhar tempo, enquanto fortaleciam suas posições militares. Um dia após as eleições norteamericanas, no dia sete de novembro, o International Herald Tribune publicou documentos secretos do governo dos Estados Unidos, em que eles se congratulavam por haver bloqueado eficazmente a proposta de paz de Contadora (VIAÑA, 1986, p. 141). Em um gesto carregado de significado político, as autoridades nicaraguenses anteciparam as eleições que estavam programadas para acontecer em 1985, para que ocorressem apenas dois dias antes das eleições norte-americanas, no dia quatro de novembro de 1984 . Os sandinistas venceram as eleições com mais de $65 \%$ dos votos

Revista Eletrônica da ANPHLAC, ISSN 1679-1061, n.15, p. 282-306, jul./dez. 2013. 
(JAKOBSKIND, 1985, p. 100). O ano terminava, porém, em um novo impasse para a pacificação da América Central.

No primeiro semestre de 1985, seguidas reuniões foram desmarcadas em razão do recrudescimento dos conflitos. O congresso norte-americano recusou uma solicitação do Executivo para maiores financiamentos aos contras, mas, em seguida, Daniel Ortega viajou a Moscou, gerando repercussões políticas negativas. Em uma nova escalada, o Congresso dos Estados Unidos aprovou novo pedido de financiamento, concedendo US\$27 milhões em ajuda humanitária para os contras. Em resposta, a Nicarágua voltou atrás em sua decisão de não comprar mais armamentos. A acusação de que aquele país era uma potência militar desestabilizadora na região era um argumento recorrente entre os apoiadores da política militarista. A reunião conjunta de Contadora, programada para maio de 1985, não se realizou, porque a Nicarágua insistiu em que os ministros deveriam se pronunciar sobre a decisão do Congresso dos Estados Unidos. Em julho, os ministros do Grupo de Contadora propuseram um plano de seis pontos para acelerar a assinatura de um acordo de paz, em reunião que aconteceu no Panamá. Houve propostas para que o Grupo se expandisse, aceitando a Argentina e outros países. Mas o México se opôs, alegando que a composição era eficaz. O México aceitava, porém, a criação de um "mecanismo de apoio". Em que pesem os obstáculos, houve quem avaliasse que o Grupo de Contadora impediu que os Estados Unidos atacassem diretamente a Nicarágua, como haviam feito com Granada em 1983 (VIAÑA, 1986, p. 156-159).

\section{Do Grupo de Apoio ao Grupo do Rio}

Seguindo a proposta mexicana, os presidentes da Argentina, do Brasil e do Uruguai se uniram ao presidente peruano que tomava posse, Alan Garcia, para formar o Grupo de Apoio a Contadora. Essa decisão foi tomada em Lima, no dia 29 de julho de 1985. Para a Argentina, essa iniciativa se inseria em um contexto no qual os laços com a Europa e os Estados Unidos estavam abalados em razão da Guerra das Malvinas. Mas também se inseriam em um contexto em que a aproximação com os vizinhos latinoamericanos, especialmente com o Brasil, dava a tônica de sua diplomacia (BANDEIRA, 2005, p. 270-271). Desde a sua redemocratização, a Argentina também se havia convertido, ao lado da Venezuela, em um dos países promotores da democracia na Revista Eletrônica da ANPHLAC, ISSN 1679-1061, n.15, p. 282-306, jul./dez. 2013. 
região. O tema da democracia não estava restrito à América Central. No Brasil, o primeiro presidente civil em 21 anos, Tancredo Neves apenas tinha sido eleito, e ainda pelo voto indireto. Havendo falecido em abril, sem ter tomado posse, fora substituído por José Sarney. No Paraguai e no Chile, ainda eram dúbios os sinais de que a volta à democracia poderia acontecer em curto prazo.

Para o Brasil, estava em jogo a ressignificação de suas relações com os vizinhos latino-americanos. O período de vigência da ditadura militar havia sido marcado pela atuação aberta em favor de soluções autoritárias, o que gerou ressentimentos na região. Desde o último governo militar, porém, o Brasil havia iniciado um movimento de aproximação, condicionado em parte pelas mencionadas dificuldades em suas relações com os Estados Unidos e pela necessidade de concertar esforços pela solução da crise da dívida externa (KLAVEREN, 1996, p. 48; OLIVEIRA, 2005, p. 199; ZURITA, 1999, p. 191). Ramiro Saraiva Guerreiro, chanceler durante o governo de João Figueiredo, já expressara o seu apoio à iniciativa de Contadora, em 1983 (GUERREIRO, 1983, p. 170-171). Esse apoio foi reafirmado pelo então candidato à presidência da República, Tancredo Neves, em exposição para a Comissão de Relações Exteriores da Câmara de Deputados, realizada entre os dias 28 e 29 de outubro de 1984 (NEVES, 1985, p. 149-158). Após a formação do Grupo de Apoio, José Sarney discursou na Assembleia Geral das Nações Unidas, em setembro de 1985, reafirmando a prioridade que seu governo devotava às negociações de paz na América Central (SARNEY, 1985, p. 175). Em novembro daquele ano, um encontro entre os presidentes do Brasil e da Argentina ratificou a conexão entre a cooperação desses dois países, em projetos de escopo bilateral e multilateral, como era o caso de Contadora (CAMARGO, 2000, p. 158; LIMA, 2000, p. 79).

Desde a entrada em cena do Grupo de Apoio a Contadora, o escopo da colaboração entre os países envolvidos passou a se ampliar. O Panamá, envolvido em uma convulsão política que culminaria na invasão norte-americana em 1989 e na prisão do comandante Manuel Noriega, já estava então afastado das atividades do Grupo de Contadora. Em uma reunião de fevereiro de 1986, realizada em Punta del Este, Uruguai, os ministros de Relações Exteriores e de Assuntos Econômicos da Argentina, Brasil, Colômbia, México, Peru, Uruguai e Venezuela debateram as perspectivas de Revista Eletrônica da ANPHLAC, ISSN 1679-1061, n.15, p. 282-306, jul./dez. 2013. 
cooperação entre devedores, para negociar uma solução para o problema da dívida e analisaram o cenário centro-americano, reafirmando os princípios originais do Grupo de Contadora e convidando os líderes dos países envolvidos em conflitos a que renovassem conjuntamente os esforços de negociação para a paz (SODRÉ, 1986, p. 145-147).

No primeiro trimestre de 1986, o diplomata venezuelano Alfredo Toro Hardy (1986) publicou um artigo na Revista de Política Internacional, em que defendia a iniciativa de paz que partia de Contadora, contra as críticas de acadêmicos norteamericanos (p. 20-22). No terceiro trimestre desse mesmo ano, a historiadora Marisol de Gonzalo (1986) voltou a assinalar a possibilidade que a iniciativa conjunta dos países latino-americanos abria para a cooperação contínua e ampliada a diversos temas (p. 1623). Em abril de 1986, o presidente da Venezuela, Jaime Lusinchi, visitou o Brasil, e afirmou ao jornal $O$ Estado de S. Paulo: "Venezuela le da una importancia muy grande al reencuentro de Brasil con la democracia ya que nada se puede hacer en América Latina sin que Brasil participe". Naquele mesmo mês, a imprensa venezuelana noticiou a venda de 30 aviões Tucano da Embraer à Força Aérea da Venezuela (ZURITA, 1999, p. 191-192). Como se vê, a cooperação política também continha um substrato material.

Tal confiança promovida entre o Brasil e seus vizinhos contrastava com uma tendência que predominara apenas alguns anos antes, de desconfiança e um certo temor quanto às pretensões geopolíticas do país. Em conferência sobre "O desafio democrático na América Latina", realizada em Lisboa, em 1984, autoridades venezuelanas ligadas ao ministério da Defesa e ao partido do governo, Ação Democrática, criticaram a Escola Superior de Guerra do Brasil (ESG), ao dizer que essa seria a inspiradora dos demais regimes militares na América do Sul e deturpadora dos princípios democráticos. Segundo os venezuelanos, a doutrina da ESG estaria marcada pela consideração do papel das forças armadas como mantenedoras da ordem e da hierarquia internas, deixando a defesa externa a cargo dos Estados Unidos, em harmonia com as doutrinas postuladas por Robert McNamara e Samuel Huntington, e menosprezando a política por considerá-la fonte de desordens (Folha de S. Paulo, 05/07/1984).

Em novembro de 1986, eclodiu nos Estados Unidos o escândalo que ficou conhecido como Irã-Contras, e que consistiu na revelação de que o governo norteamericano vendera secretamente armas para o seu inimigo, o governo do Irã, para Revista Eletrônica da ANPHLAC, ISSN 1679-1061, n.15, p. 282-306, jul./dez. 2013. 
financiar as operações de guerrilha na América Central (SANTOS, 2007, p. 42). Nesse contexto, em que os Estados Unidos tiveram sua atuação política enfraquecida, e na qual os países do Grupo de Contadora e do Grupo de Apoio tinham dificuldades em fazer avançar sua agenda para a América Central, o presidente da Costa Rica, Oscar Arias, apresentou, em fevereiro de 1987, um plano de paz que estipulava um cessarfogo na região por 90 dias, além da anistia aos presos políticos, do fim da ajuda externa aos rebeldes e da promoção de diálogos de reconciliação nacional e da democracia no interior dos países da região. A proposta conservava muito traços do que havia sido proposto pelo Grupo de Contadora nos anos anteriores e foi bem recebida entre os países latino-americanos, garantindo ao presidente da Costa Rica o prêmio Nobel da Paz de 1987 (AYERBE, 2002, p. 207).

No mês seguinte, os chanceleres dos Grupos de Contadora e de Apoio se reuniram no Rio de Janeiro, aonde concordaram em estabelecer, em caráter permanente, um Mecanismo de Consulta, que passou a ser conhecido primeiramente como Grupo dos Oito e, mais tarde, Grupo do Rio. O propósito declarado do Mecanismo de Consulta era "fortalecer e sistematizar a concertação política de nossos Governos, através de um processo de consultas regulares sobre temas que afetam ou interessam a nossos países, no contexto de uma crescente unidade latino-americana" (GRUPO DO RIO, 1995, p. 29; SILVA, 1989, p. 5). Sobre essa evolução dos mecanismos de cooperação política, Luiz Felipe de Seixas Corrêa (1996) escreveu:

A decisão de participar no Grupo de Apoio a Contadora revelou-se acertada.
Credenciou o Brasil para ações efetivas no plano regional e deu origem ao
que viria a ser posteriormente conhecido como Grupo do Rio. Criou-se pela
primeira vez na América Latina um canal autônomo de ação diplomática,
habilitado a discutir e influenciar políticas sobre as principais questões
regionais sem a participação ou a tutela dos EUA. (p. 373 )

À medida que as negociações de paz na América Central se encaminhavam nos moldes propostos pelo presidente da Costa Rica, as reuniões do Mecanismo de Consulta se sucederam e ampliaram a pauta de assuntos para a cooperação internacional. Já na primeira Reunião Ordinária Ministerial, realizada em Bariloche, no dia 16 de abril de 1987, o Grupo ampliou sua agenda para os seguintes temas, além da questão da América Central: dívida externa, desenvolvimento tecnológico, formação do Parlamento

Revista Eletrônica da ANPHLAC, ISSN 1679-1061, n.15, p. 282-306, jul./dez. 2013. http://revista.anphlac.org.br/ 
Latino-Americano, aspectos jurídicos da integração (especialmente comercial), segurança alimentar e luta contra a pobreza. Esses temas também foram tratados na segunda Reunião Ministerial, que aconteceu no dia 11 de agosto do mesmo ano, em Campos do Jordão, Brasil. Após essa reunião, os ministros do Grupo mantiveram conversações com representantes da Comunidade Econômica Europeia, no período de realização da Assembleia Geral das Nações Unidas, em setembro de 1987, dando início ao relacionamento oficial do Grupo com atores extrarregionais (GRUPO DO RIO, 1995).

Ao longo dos anos seguintes, diversas reuniões ministeriais se intercalaram com reuniões presidenciais, ampliando sempre o escopo dos temas tratados no interior do Grupo. Na primeira Reunião Presidencial, que aconteceu em novembro de 1987, em Acapulco, México, foram combinadas ações conjuntas no âmbito da ONU e do Acordo Geral de Tarifas e Comércio (GATT). Naquela ocasião, o chanceler venezuelano declarou:

\footnotetext{
Pocos se enteraron de que en Río nos congregaba un propósito diferente al de América Central y sus conflictos: el esfuerzo realizado mediante el proceso negociador de Contadora representaba una inversión demasiado importante en la política exterior de los países miembros para desaprovecharla circunscribiéndola a un solo asunto, sin menospreciar la importancia del mismo (RANGEL, 1988, p. 12).
}

Na Terceira Reunião Ministerial, realizada em Cartagena de Índias, Colômbia, em fevereiro de 1988, também foram discutidas propostas de cooperação no âmbito da OEA e em matéria de combate ao narcotráfico. Na Quarta Reunião Ministerial, que aconteceu em Oaxaca, México, em junho de 1988, foram feitas propostas de aproximação com o Japão, com a Associação de Nações do Sudeste Asiático (ASEAN), com o Conselho dos Países Nórdicos e com a Organização da Unidade Africana (OUA). A Segunda Reunião Presidencial, realizada em Punta del Este, Uruguai, no dia 29 de outubro de 1988, marcou a entrada da cooperação em matéria ambiental. Dessa maneira, sucessivas reuniões foram se realizando periodicamente, até que a Sexta Reunião Ministerial (Buenos Aires, dezembro de 1989) conferiu uma prioridade, até então inédita, aos aspectos comerciais da integração latino-americana, certamente influenciada pelas ideias neoliberais de liberalização comercial então em voga (GRUPO Revista Eletrônica da ANPHLAC, ISSN 1679-1061, n.15, p. 282-306, jul./dez. 2013. 
DO RIO, 1995). Essa mesma Reunião foi a última a produzir um documento, em que os chanceleres se referiam ao Grupo dos Oito. A partir das reuniões seguintes, o nome adotado passou a ser Grupo do Rio, tal como existiu até 2010, quando foi rebatizado Comunidade de Estados Latino-americanos e Caribenhos (CELAC).

Ao longo das reuniões, se formou também uma espécie de cláusula democrática implícita, que levou à suspensão temporária do Panamá após agitações de 1988. A incorporação do combate ao narcotráfico, a partir da Terceira Reunião Ministerial, se harmonizava com a política de Ronald Reagan para o assunto, que favorecia a repressão nas áreas de produção, vinculando o tema à segurança nacional e contornando as dificuldades associadas com a repressão da demanda interna aos Estados Unidos (AYERBE, 2002, p. 213) Esse fato, juntamente com a aceitação das teses neoliberais, demonstra que a oposição entre o Grupo de Contadora e os Estados Unidos foi sendo diluída à medida que os temas se foram ampliando.

O movimento de formação de parcerias extrarregionais promovido pelo Grupo do Rio, desde 1988, ganhou significativo incremento com o resultado das eleições de dezembro daquele ano na Venezuela. $\mathrm{O}$ vencedor das eleições, empossado em fevereiro de 1989, foi o ex-presidente Carlos Andrés Pérez, que, em sua primeira passagem pelo gabinete presidencial (1974-1979), se notabilizou pela intensa atividade diplomática. Naquele período, Andrés Pérez manteve a cooperação com os países da Organização dos Países Exportadores de Petróleo (OPEP), ao mesmo tempo em que planejou e executou programas de cooperação econômica com os países da América Central e do Caribe. Em sua cerimônia de posse, a Venezuela recebeu a visita do presidente brasileiro, José Sarney. Foi a primeira visita de um presidente brasileiro a uma cerimônia desse tipo na Venezuela. Também compareceram os presidentes de Cuba, Fidel Castro, e da Nicarágua, Daniel Ortega, além do ex-presidente dos Estados Unidos, Jimmy Carter, e o vice-presidente recém-eleito daquele país, Dan Quayle. Somaram-se a eles o primeiro-ministro espanhol, Felipe Gonzalez, o português, Mario Soares, e o alemão, Willy Brandt, compondo prestigiosa delegação da Internacional Socialista. Ao todo, compareceram 25 chefes de Estado e 700 autoridades e personalidades estrangeiras. A credibilidade do novo presidente venezuelano era tanta, que na véspera de sua posse, Daniel Ortega manteve encontro em Caracas com o líder dos rebeldes, Revista Eletrônica da ANPHLAC, ISSN 1679-1061, n.15, p. 282-306, jul./dez. 2013. 
Alfredo Cesar (O Estado de S. Paulo, 02/02/1989; Folha de S. Paulo, 02/02/1989). O prestígio internacional de Carlos Andrés Pérez abriu caminho para que se implementassem, a partir do ano seguinte, reuniões ministeriais regulares com representantes da Comunidade Econômica Europeia (GRUPO DO RIO, 1995).

A guerra continuava na América Central, embora os encontros para a negociação de um plano de paz, baseados na proposta do presidente da Costa Rica, prosseguissem. O cronograma se desenvolvia desde o primeiro encontro na cidade de Esquipulas, na Guatemala, em maio de 1986. Esse encontro ficou conhecido como Esquipulas I. Novamente naquela cidade, em agosto do ano seguinte, os presidentes dos cinco países (Costa Rica, El Salvador, Guatemala, Honduras e Nicarágua) assinaram os Procedimentos para o Estabelecimento de uma Paz Firme e Duradoura na América Central. Os presidentes acordaram cessar as hostilidades nos conflitos armados, suspender os estados de emergência, restabelecer a liberdade de imprensa, restabelecer garantias constitucionais, conceder anistia aos presos políticos, iniciar diálogos com os membros da oposição e interromper o recurso ao apoio estrangeiro para operações militares. Além disso, no âmbito internacional, foi criada a Comissão Internacional de Verificação e Acompanhamento, integrada por representantes dos secretários gerais das Nações Unidas e da OEA, e pelos chanceleres dos cinco países centro-americanos e mais os oito chanceleres do Grupo do Rio. Esses foram os termos do acordo que ficou conhecido como Acordo da Guatemala ou, mais comumente, Esquipulas II (DIÁLOGO INTERAMERICANO, 1988, p. 3-4).

O acordo não foi integralmente cumprido, e, em diversos casos, houve recrudescimento imediato dos conflitos, com os exércitos beligerantes buscando fortalecer suas posições. Ao longo dos meses, porém, diversas modificações favoráveis aconteceram. Em El Salvador, recomeçaram as negociações de paz entre o governo e os rebeldes. Refugiados foram repatriados e prisioneiros libertados. $\mathrm{Na}$ Guatemala, houve reunião entre membros do governo e rebeldes, pela primeira vez em 27 anos, e exilados visitaram o país. Em Honduras, assumiu-se o compromisso de desmantelar acampamentos dos contras que lutavam na Nicarágua, além de auxiliarem na repatriação de refugiados. Na Costa Rica, também foram tomadas medidas para neutralizar os contras. Na Nicarágua, foi estabelecida a Comissão de Reconciliação Revista Eletrônica da ANPHLAC, ISSN 1679-1061, n.15, p. 282-306, jul./dez. 2013. 
Nacional, prisioneiros foram libertados, veículos de imprensa foram reabertos, exilados regressaram e diálogos foram estabelecidos com grupos indígenas resistentes. Ainda no início de dezembro de 1987, iniciaram-se negociações indiretas com os contras, algo que o governo na Nicarágua havia se recusado a fazer até então. Em janeiro de 1988, aconteceu uma reunião dos cinco presidentes, e a Nicarágua anunciou que suspenderia o estado de emergência e restauraria as garantias constitucionais. As negociações com os contras começaram fora da Nicarágua, mas, em março de 1988, aconteceu uma reunião em Sapoá, território nicaraguense. Em 24 de março de 1988, chegaram a um acordo de trégua de 60 dias, em que um cessar-fogo permanente seria negociado. O governo se comprometeu a liberar prisioneiros, e os rebeldes deveriam se concentrar em áreas designadas, aonde receberiam ajuda humanitária vinda de organizações neutras. (DIÁLOGO INTERAMERICANO, 1988, p. 5-7).

Ainda que a paz não tenha sido integralmente alcançada naquela região, fato que só viria a se concretizar já na década de 1990, os atores envolvidos na coordenação dos Grupos de Contadora e de Apoio, que se fundiram no Grupo dos Oito, depois chamado Grupo do Rio, consideraram que o encaminhamento das negociações em seus termos fora uma importante vitória política. Além disso, a formação de um Grupo articulado em função dos problemas específicos da região foi um dividendo dos esforços daquele período. Assim considerou German Nava Carrillo (1988), ex-chanceler da Venezuela, quando escreveu: "a través de la concertación aumenta considerablemente nuestro poder de negociación en la escena internacional” (p. 4).

Na Quarta Reunião Presidencial, realizada em Caracas, no mês de outubro de 1990, os presidentes saudaram a Iniciativa para as Américas, plano proposto pelo governo norte-americano chefiado por George Bush, que pretendia normalizar os pagamentos da dívida externa, através de um novo sistema de negociações, normalizando também o fluxo de capitais para os países latino-americanos. A Iniciativa para as Américas compreendia também um processo de liberalização comercial. Dessa forma, o Grupo do Rio abrandou as possibilidades de atrito com os Estados Unidos, que remontavam à oposição que o Grupo de Contadora havia feito à sua política para a América Central. Naquela mesma reunião, ficou acertada a troca de informações para a reforma do Estado, que a maioria dos países executava para reorganizar suas economias

Revista Eletrônica da ANPHLAC, ISSN 1679-1061, n.15, p. 282-306, jul./dez. 2013. 
de acordo com o paradigma neoliberal vigente. Bolívia, Paraguai, Chile e Equador foram admitidos ao Grupo, que assumiu a partir daí uma feição nova, distanciada do propósito inicial de promoção da paz na América Central e muito mais voltada para a modernização econômica e institucional dos países participantes, em cooperação com a Comunidade Econômica Europeia e com os Estados Unidos (GRUPO DO RIO, 1995, p. 164-167 e 315).

\section{Considerações Finais}

O caráter recente dos eventos aqui analisados faz com que eles não tenham constituído um tema muito visitado na historiografia latino-americana. A análise das fontes, contudo, revela um momento crucial na construção de um ambiente de confiança e cooperação na América Latina. A década de 1980 não foi apenas um momento propício para a construção dessa confiança. Foi também um período repleto de crises (da dívida externa, da violência na América Central, da redemocratização) e ressignificações, fazendo com que, no campo das relações internacionais da América Latina, esteja longe de se constituir em uma "década perdida".

O fechamento dos canais de financiamento externo que a crise da dívida externa acarretou, somada à queda nos preços dos produtos exportados pelos países latinoamericanos no mercado internacional e a agressividade militarista demonstrada pelos Estados Unidos durante os dois governos de Ronald Reagan (1981-1989) propiciaram um contexto favorável à introspecção da região, em que os países envolvidos valorizaram, de maneira inédita, os laços geográficos, linguísticos e culturais que os unem para construir também laços políticos fortalecidos.

No contexto da iniciativa de pacificação do Grupo de Contadora, países que tinham laços deteriorados por anos de autoritarismo puderam ressignificar as relações com os seus vizinhos, tornando-se partícipes e protagonistas em um processo de coordenação de políticas, que logo se estendeu para muito além do que o problema das guerras na América Central. Especialmente o Brasil, que durante décadas evitou maiores compromissos, multilaterais e bilaterais, com os seus vizinhos, pôde construir uma relação cooperativa com a Argentina e com a Venezuela. Tais relações foram eixos fundamentais, utilizados no processo de multilateralização da diplomacia brasileira.

Revista Eletrônica da ANPHLAC, ISSN 1679-1061, n.15, p. 282-306, jul./dez. 2013. 
Para a Venezuela, os anos 1980 foram ocasião de um protagonismo muito intenso no contexto da política regional. Caracas sediou diversos encontros que foram importantes para a construção e aprofundamento do Grupo do Rio e chegou mesmo a sediar um encontro entre o presidente da Nicarágua e o líder das forças rebeldes naquele país. Poucas cidades teriam condições de reunir, em uma mesma ocasião, representantes cubanos, nicaraguenses, soviéticos e norte-americanos, como fez Caracas.

\section{Referências Bibliográficas}

ALBUQUERQUE, José A. G. (Org.). Sessenta anos de política externa brasileira 1930-1990. O Desafio Geoestratégico. Vol. III. São Paulo: Annablume/NUPRI/USP, 2000.

Sessenta anos de política externa brasileira (1930-1990). Crescimento, modernização e política externa. São Paulo: Nupri-USP; Cultura Editores Associados, 1996.

ARAVENA, Francisco Rojas; RIVERA, Luis Guillermo Solís. Central America and the United States. In: MUÑOZ, Heraldo; TULCHIN, Joseph S. (Orgs.). Latin American Nations in world politics. 2 ed. Boulder: Westview Press, 1996. p. 105-128.

AYERBE, Luis F. Estados Unidos e América Latina: a construção da hegemonia. São Paulo: Editora UNESP, 2002.

BANDEIRA, Luiz A Moniz. Formação do império americano. Rio de Janeiro: Civilização Brasileira, 2005.

GUIMARÃES, Samuel P. (Org.). Brasil e Venezuela: esperanças e determinação na virada do século. Brasília: Instituto de Pesquisa de Relações Internacionais; Fundação Alexandre de Gusmão, 1995.

JAKOBSKIND, Mário A. América Latina: histórias de dominação e libertação. Campinas: Papirus, 1985.

OLIVEIRA, Henrique A. de. Política externa brasileira. São Paulo: Saraiva, 2005.

SANTOS, Marcelo. O poder norte-americano e a América Latina no pós-guerra fria. São Paulo: Annablume; Fapesp, 2007.

SERBÍN, Andrés. Venezuela, el "Gran Viraje” y el Caribe. In: Revista Política Internacional, n.29, p. 10-14, 1993.

KLAVEREN, Alberto van. Understanding Latin American foreign policies. In: MUÑOZ, Heraldo; TULCHIN, Joseph S. (Orgs.). Latin American Nations in world politics. Boulder, EUA: Westview Press, 1996. p. 35-60.

VIAÑA, Fernando Murillo. América Latina en los ochenta. Madri: Ediciones Cultura Hispánica, 1986.

Revista Eletrônica da ANPHLAC, ISSN 1679-1061, n.15, p. 282-306, jul./dez. 2013. 
VIZENTINI, Paulo F. O descompasso entre as nações. Rio de Janeiro: Record, 2004.

ZURITA, Alejandro Mendible. Venezuela-Brasil: la historia de sus relaciones desde sus inicios hasta el umbral del Mercosur (1500-1997). Caracas: FEPUVA, 1999.

\section{Relação das Fontes}

Os jornais brasileiros foram consultados na Hemeroteca do Senado Federal, onde estão compilados segundo pastas temáticas. Foram consultadas as reportagens armazenadas nas pastas temáticas da "Venezuela". Os periódicos consultados foram: Correio Braziliense, Folha de S. Paulo, Jornal de Brasília, Jornal do Brasil, O Estado de S. Paulo.

A Revista Política Internacional, publicação venezuelana que circulou entre 1986 e 2000, foi consultada integralmente. Os números que foram publicados até 1990 foram utilizados como fontes que revelaram o estado das discussões naquele momento:

CARRILLO, Germán Nava. La búsqueda de la unidad y la concertación de América Latina. In: Revista Política Internacional, n. 11, p. 1-5,1988.

GONZALO, Marisol de. La Significación del Grupo Contadora como Actor Internacional. In: Revista Política Internacional, n. 3, p. 16-23,1986.

SILVA, Elsa C. da. La política exterior de Venezuela 1984-1989: entre las vulnerabilidades económicas y los compromisos políticos. In: Revista Política Internacional, n. 14, p. 1-14, 1989.

TÓRTORA DE RANGEL, Manuela. Una innovación en la Cooperación Latinoamericana: El Grupo de los Ocho. In: Revista Política Internacional. Caracas, n. 11, p. 12-15,1988.

A Revista Brasileira de Política Internacional publicou artigos e documentos relevantes na área de política internacional:

ALEIXO, José C. B. O Brasil e a América Central. In: Revista Brasileira de Política Internacional. N. 101-104, Ano XXVI, p. 21-58, 1983.

GUERREIRO, Ramiro S. Entrevista ao jornal O Globo. In: Revista Brasileira de Política Internacional. N. 101-104, Ano XXVI, p. 163-171, 1983.

NEVES, Tancredo. Exposição à Comissão de Relações Exteriores da Câmara de Deputados. In: Revista Brasileira de Política Internacional. N. 109-110, Ano XXVIII, p. 149-158, 1985.

SARNEY, José. Discurso perante a Assembleia Geral das Nações Unidas. In: Revista Brasileira de Política Internacional. N. 111-112, Ano XXVIII, p. 170-179, 1985.

Revista Eletrônica da ANPHLAC, ISSN 1679-1061, n.15, p. 282-306, jul./dez. 2013.

http://revista.anphlac.org.br/ 
SODRÉ, Roberto de A. Consenso de Cartagena e Grupo de Contadora. In: Revista Brasileira de Política Internacional. N. 113-114, Ano XXIX, p. 145-147, 1986.

Outras coleções de documentos:

AS AMÉRICAS EM 1988: Tempo de Opções. Um Relatório do Diálogo Interamericano. Washington: Aspen Institute for Humanistic Studies, 1988.

GRUPO DO RIO: documentos do mecanismo permanente de consulta e concertação política. Brasília: FUNAG, 1995.

Revista Eletrônica da ANPHLAC, ISSN 1679-1061, n.15, p. 282-306, jul./dez. 2013. http://revista.anphlac.org.br/ 